\title{
Beyond the Barriers of Nature: Critical analysis of views on God's Existence in various religions
}

\author{
R. Rafique, N. Abas
}

Department of Electrical Engineering, University of Gujrat, Hafiz Hayat Campus, Gujrat

\begin{abstract}
This article reports critical overview of views on existence of God and naturalism. Theists argue the existence of God, atheists insist nonexistence of God, while agnostics claim the existence of God is unknowable, and even if exists, it is neither possible to demonstrate His existence nor likely to refute this spiritual theology. The argument that the existence of God can be known to all, even before exposure to any divine revelation, predates before Islam, Christianity and even Judaism. Pharos deity claim shows that the concept of deity existed long before major religions. History shows the Greek philosophers also tried to explore God before, during and after the prophet's revolution in Mesopotamia. Today presupposition apologetical doctrine (Abram Kuyper) ponders and defends the existence of God. They conclude the necessary condition of belief to be exposed to revelation that atheists deny calling transcendental necessity. Human experience and action is proof of God's existence as His existence is the necessary condition of human being's intelligibility. The spirituality exists in all human sub-consciousness and sometimes, reveals to consciousness of some individuals. Human being's inability to conceive the cosmos shows that there exist more types of creatures in different parts of universe. Enlightened men's capability to resurrect corpse proves soul's immortality. Questions like poor or the intelligent design and external or internal search for exposure of revelation have been discussed in context of theism and atheism doctrines. Based on philosophical views it will be endeavored to imagine beyond time-space barriers.
\end{abstract}

Keywords: God; Allah; Muhammad; Naturalism; Theist

\section{Introduction}

The human being, regarding faith, may be divided in three categories namely theists (believers), atheists (nonbelievers) and agnostics (doubters). Over 8 billion masses conflict with one another ever since either over clash of civilizations or religious beliefs. Philosophers, theologians, scientists, capitalists (entrepreneurs, industrialists, consumerists) and communists (Marxists, Leninists and Maoists) have formed multiple schools of thought on epistemology of the ontology of God. Words like God (Christians), Allah (Muslims), Yavee (Jews) and Brahman (Hindus) are used to refer to the ultimate authority empowering the wheel of the nature. The last prophet Muhammad (PBUH) gave 99 names of God regarding His power, kindness, anger, wisdom and justice etc. Monotheists, as well as Polytheists (Pantheists or Henotheists), believe in God's omniscience, omnipotence and benevolence. The believers (theists) use metaphysical (beyond materiality), subjective (based on feelings), empirical (verifiable) and inductive (logical and based on accepted laws) arguments for the existence of God whilst the Atheists and Agnostics (cynics, disparagers and skeptics) rejecting metaphysical and subjective approaches endeavoring empirical, deductive (based on accepted principles) and inductive arguments against the existence of God. Agnostics think it is not possible to prove existence of God or nothingness. By faith, the man being part of physical nature cannot think of metaphysical reality. God being creator of physical nature is not bound to obey the physical laws governing nature. Human, being 


\title{
$5^{\text {th }}$ International Conference on Research in Behavioral and Social Science
}

\author{
Spain | Barcelona | December 7-9, 2018
}

part of physical world cannot think of the existence of God beyond natural barriers. Academia never touched this topic in last five centuries, but the question of existence of God has become again lively debatable issue in philosophy (Copan, 2003) as well as science (Hoodbhoy, 2009). People usually differ on "Existence of God" due to their differences of conception on term "proof", "truth", "false" and "knowledge". Revelation and enlightenment are a priori class of knowledge which means differently among various religions. There is little hope of success to realize the origin of ultimate oneness. Nevertheless, this article attempts to analyze the reported opinions and outlooks beyond the frontiers of nature.

All nonbelievers (who do not believe in any ultimate God) are united globally, but the believers (who believe in an ultimate God) are at wars with one another for materialistic and monetary gains (black gold) calling their opponents nonbelievers. Believers are further divided in subgroups on more exceptional details of their beliefs. Muslims are divided into Sunni, Wahabi, Shee' a and other factions; Christians in Protestants, Catholics, Unorthodox and Orthodox factions; Jews in extreme fundamentalists and capitalists; and Hindus in Brahmans, Khhatris and Untouchables etc. Historically, Hindus were known for idolatry, but recently they have managed to prove their belief in one ultimate nirguna Brahman who appears as Ishvara to talk to people. After great deluge, the East and West worshipped stone statues. Abraham erected Kaba several thousand years earlier in Mecca, and Muhammad put end on idolatry in peninsula Arabia just 1500 years ago.

Except Hindus, Muslims, Christians and Jews believe in Abraham descendants messenger prophets whom their holy books like Testament, Bible and Quran were revealed. However, the recorded history of the Hinduism goes back quite a few thousand years ago. Names of 20-24 prophets are listed in Bible and Quran, but arrival of more prophets is mentioned in Quran. Few analysts consider imaging the possibility of unnamed prophets leading Hindus, Buddhists and earlier religions. There is a fundamental difference between believers and nonbelievers on creation or evolution of human being. Theologians believe the human being was sent to earth, but atheists believe in the evolution skepticism. Scientists and philosophers are also divided over concept of deity and natural evolution. The geological and archeological studies show the remains of man in its present form started appearing since 50006000 BCE. It means the first man (Adam) and woman (Eve) came to earth maximally 7000-8000 years ago (Wallach, 2007).

Professor Pervez Hoodbhoy (Hoodbhoy, 2009) divides the global population on basis of culture, politics, religion and race but Ian and Phillips part the global community under two-culture theory of pessimists and optimists (Ferry, 2009). Barnaby's opinion on water as bone of contention between nations (Barnaby, 2009) was opposed by Egyptian Serageldin (Serageldin, 2009) but supported by Israeli Shamir (Shamir, Grand, \& Grand, 2009). IPCC warns of global warming, but a huge number of scientists warn of global cooling. Both, heat strokes, as well as snow blitz theories, are supported by scientifically acceptable empirical, inductive and deductive arguments. It means the scientific methods are not enough to analyze even physical nature rather than the metaphysical world. After inventing the relation between mass (matter) and energy (virtual) $\mathrm{E}=\mathrm{mc}^{2}$, Albert Einstein said, "I want to know the thoughts of God the rest is all detail," He might have learned the God's thoughts but is unable to tell to others. Many learned philosophers, like Allama Muhammad Iqbal, reached the stage of recognising revelation but could not explain to others despite being western literate having command on multiple languages. He said "God! Give others my noor-e-basirat (spiritual vision). We are preoccupied by so many unanswered precedence questions like hen or egg, evolution or creation, man or monkey, brain 
or heart, mind or body and earth or heavens etc. AAAS has published so many questions that the scientific wisdom cannot answer (Jr., 2008).

\section{Existence of God}

Empirical, inductive and deductive science methods without incorporating subjective and metaphysical approaches and testimonies lead us to nowhere. Soloman had a miraculous power to tame giants to do physical jobs. He ordered giants to build mosque Al-Aqsa in Jerusalem that stands to date. Idea of harnessing giants to drive electric generators to produce electricity is pretty impressive. Future Indian ghost busters might conduct spiritual cum monetary business to compete MicrosftTM and lab on chip system developers. Science and engineering doctrines restrict both capitalists and communists to keep within the peripheries of industrial and economic domains that have nothing to do with metaphysical realities of creation and resurrection. Nonbelievers have started using science ethic codes not to let believers to write and speak word God. Chief Editor of Sustainable and Renewable Energy Reviews journal (Elsevier), Mr. Kazmari, has committed to retract an energy review research paper (Khan, Saleem, \& Wahid, 2007) because the author used word "God" in conclusions. He also refused to publish another accepted paper commenting energy crisis/war (Abas, Kalair, \& Khan, 2015). If the science cannot controvert the "existence of God" then using word "God" in technical reviews on chaotic situations must not be taken so seriously. When believers can afford to listen and read nonbeliever's yap and yelp then why they roll up their eye balls on hearing and reading word "God". When we isolate our minds, then truth cannot reach the skull. Even the editor wrote hatefully asking "Which God, He or She". I come from liberal democratic Pakistan, not from police state of Germany, Russia, China and United States America where government's permissions might be required to speak the truth. We have to spare moments from knowledge based economic race to ensure the correctness of destiny.

Believing in multiple gods, polytheism, compared to the single omniscient, omnipotent and benevolent Ultimate Being or Prime Mover or Uncaused Cause or Ultimate Creator, monotheism, is the major rift among believers. Pantheists such as Spinoza and Einstein refer the term God to the essential substance/principles of nature (Abbott, 2002). Muslims and Jews are monotheist whereas Christians and Hindus are polytheists. Muslims believe the real God has created the nature. Neither someone borne Him nor He has borne anyone out of Him. He was, is and will remain forever, and everything else has a definite lifespan. Polytheists use the word "go" for multiple being with varying degrees of power and abilities to which monotheist ascribe to be God gifted miracles. Muslims believe the God is the Supreme Being and it "Shrk = attempt to equate by sharing deity powers" to assume creatures sharing divine power. Quran calls such people "Mushrkeen = equating creature to creator to share deity powers" and threatens great punishment for them after resurrection.

Epistemologically knowledge is the sense of "understanding of a fact or truth" may be posteriori (based on experience or deductions) or priori (observation or self-evidence). The knowledge is a psychological state of mind which may change over time. A common idea among most believers is "God is not the part of natural order" rather God is ultimate creator of nature including scientific laws. Many believers think to call physical laws after discover such as Newton's Law or Ohm's Law is also "Shrk" as they are not the creator of the nature (Maududi, 2000). Polytheists such as Christians due to trilemma (God, May and Jesus), Hindus due many male and female gods (nirguna Brahman and Saguna or Ishvara) etc. are regarded as mushrkeen by Muslims being monotheist. Theologians often put up divine nature of God as a proof of existence which philosophers and scientists regard a 


\title{
$5^{\text {th }}$ International Conference on Research in Behavioral and Social Science
}

\author{
Spain | Barcelona | December 7-9, 2018
}

non-falsifiable hypothesis as it falls outside the scientific investigation. Religious scientists believe the scientific research after discovering molecule, atom, electron and quark has reached frontiers of materiality "dark matter" that might be the border region between physical and spiritual worlds. Theologians are more curious on nanoscale and cosmological discoveries as they think the science might prove their true belief on existence of God.

Downward journey from molecules, atoms, electrons to quarks at nano(109)-Zepto(1021)Rimto(1045)-Lunto(1063) scales and upward journey from earth, solar system, galaxy and expanding cosmos at Giga(109)-Zetta(1021)-Rinta(1045)-Luma(1063) scales will eventually carve out the truth if materials continue to support most profound and highest scientific research. The fact is the matter starts behaving nonlinearly at few tens of nanometer scale and time intervals become limited beyond exaseconds due to materials limitations. Mass becomes non-weighable beyond tredagram (1039), the mass energy of earth; length becomes immeasurable beyond pekrometer (1039), the universal wavelength; and time becomes unfathomable beyond rimtosecond (10-45) due to Planks time constant. Scientists have set goals beyond common sense on numbers regarding googoles (10100) such as Hawking process and 10101010 the Poincare recurrence period. Matter beyond 1070kg mass starts converting into liquid itself due to tunneling effects. Mass starts converting into energy at rimtosecond (10-45) time intervals (Khan, N.; Saleem, Z.; Abas, 2008). Science cannot measure the volumetric periphery of cosmological balloon as the space time curve is expanding at a speed much greater than the supersonic jets prowling around the borders. Empirically, deductively and inductively a cyclist at $10 \mathrm{~km} / \mathrm{hr}$ speed cannot catch the accelerating car driver at $100 \mathrm{~km} / \mathrm{hr}$. It is impossible to go to or beyond the space-time curve with existing tools and technologies. To measure rimtometer with a meter or even a wavelength (pico to femtometers) is like trying to measure $1 \mathrm{~nm}$ with $1 \mathrm{~km}$ ruler. It lies in scientific domain, but science has its limitations that are neither able to imagine the smallest nor the most substantial physical quantities. Physical realities in science often seem more hypothetical than the theologian's hypothesis of the existence of God with supernatural powers. Anchoring empirical, deductive, and inductive principles, believers of intelligent design of irreducible complexity point to the existence of an intelligent creator. Perhaps we need to find inside instead of horizons.

Literate theist scientists are happy to note the dynamic fine-tuned cosmological constants to favor development of life. Measurements show the earth's magnetic poles continue to float dynamically to support the global geomagnetic system or vice versa. Theologians also believe God has created universe in six days and sky system in one day (anthropic principle) for human being long ago before sending (rather than creating) human being on planet. However, earth's suspension in air without any support at appropriate distance from Sun is manifestation of His ultimate wisdom and spiritual power that we see. It is perfect scientific domain the search the cause examining the effects. However, God is neither an entity nor a mathematical object. We cannot do experiments on God as being the creator of nature, and physical laws is not necessarily bound by them (Polkinghorne, 2003).

However, the scientific investigations may help to trace back the effects to envision the cause. If skeptics are looking for applying scientific methods to prove the existence of God, unfortunately, it would not succeed due to its limited bandwidth. Physical nature bandwidth (effect not the cause) is perceived from 10-99 to 10+99 in theories, 10-63 to 10+63 (Lunto-Luma) in literature, 10-24 to 10+24 (Yockto-Yotta) in standards and 10-18 to 10+18 (Atto-Exa) in experiments. The science has reached 


\title{
$5^{\text {th }}$ International Conference on Research in Behavioral and Social Science
}

\author{
Spain | Barcelona | December 7-9, 2018
}

from zero to Atto-Exa levels since antiquity to date and is progressing from last one decade to ascend from Atto-Exa to Zepto-Zetta levels. Human being since last 7000-8000 years has attained an excellent progress rate but still requires many centuries to reach to Rimto-Rinta levels. Scientists of aware of $0.1 \mathrm{~Hz}$ (ELF) to Gamma rays $(1017 \mathrm{~Hz})$ but the nature may not cut off bellow beyond above ranges. We can see through a limited band of $400-700 \mathrm{~nm}$ wavelengths that is just a fraction of infinite spectral frequency ranges. If we discuss the topic of spread spectrum and wireless telecom realities with a person of tenth century or even any layman American, he will not believe this reality despite it exists. Today's scientists mimic the tenth century layman perspective over modern dimensions, depths and widths spread over out-of-nothing to infinite layers of complexities. We being unaware of the genesis and the great encounter fear to write and speak pessimistic in pursuance of personal greed, gains and interests. Theologians make one worldview more significantly likely than the other. Existence of the God and naturalism are two distinct hypotheses which can neither be proved nor refuted, and the arguments of theists versus atheists bear equal weights.

Teleological (object oriented), cosmological and ontological (nature of being) arguments facilitate human being to explain complexities, cause of effects and conceiving what cannot be perceived by believing in the existence of God. Plantinga (Plantinga, 1998) formulated argument to show that if it is logically possible for God (a necessary being) to exist, then God exists. The researchers are working on mind-body problem through relation of consciousness to materiality regarding God. Existence of epiphenomena like object morality, justice and anthropic argument depends on the existence of God. Transcendental evidence for existence of God suggests that logic, science, ethics and attitudes make no sense if there is no God. Will to believe doctrine proves that adoption of theism as a hypothesis works in believer's life. Pragmatic theory of truth (hypotheticodeductive method) shows the beliefs are determined by how they work when adopted rather than by proofs before they are believed. Arguments based on miracles, revelations and enlightenment wrought by God in history hardly affect the scientists and philosophers but the existence of layered never ending complexities (intelligent design) in nature and spirits of morality and ethics in terms of individual characters and cultures may affect human being of modern age. Proof for the existence of God has much higher probability but not absolute certainty, which may only be achieved by adopting the faith (Root, 1980).

It is principle of rationality that one should accept testimony (as claimed by prophets) unless there are strong reasons for not doing so (Swinburne, 1997). Miracles shown by prophets rely on the testimony of supernatural events to establish the existence of God. Presence of theists throughout the recorded history of human being in different places is a manifestation of the prima facie of God's existence. Muslims (monotheist) believe the doomsday will occur right after the end of last monotheist from planet earth. Scotch school of philosophy accepts the existence of God without the reasons but by natural impulse. Existence of God is one of the metaphysical principles that we agree not because they are evident in themselves or because they can be proved, but because common sense obliges us to take it. Argument of proper basis proves that belief in God is a properly essential such as air, fire and water that can neither be falsified not proved. German School of Friedrich Heinrich Jacobi distinguishes sense, reason and understanding as three faculties. The thought has immediate perception of material so has reason immediate perception of the immaterial, while the understanding brings these perceptions to our consciousness and unites them to one another (Stockl, 1883). God's existence, then, cannot be proved. J-J Rousseau said "when our understanding ponders over the existence of God it encounters nothing but contradictions; the impulses of our hearts, 
however, are of more value than the understanding, and these proclaim clearly to us the truths of natural religion, namely, the existence of God and the immortality of the soul". Schleiermacher assuming an inner religious sense using which we feel religious truths said "religion consists solely in this inner perception, and dogmatic (argue) doctrines are inessential'.

Existence of God cannot be demonstrated as we cannot prove many things on record or in court which are otherwise true. The certainty to "God's existence" truth is only possible by inner experience, feeling and perception. According to the modern believers, we can only know something of God using the vital immanence (existence), that is, under favorable circumstances, the need of the Divine dormant (quiescence) in our sub-consciousness becomes conscious and arouses that religious feeling or experience in which God reveals himself to us. X Pius said, "By the natural light of reason, God can be known through His visible works of creation, as the cause is known through its effects". There seems to be none capable of dangling galaxies, orienting stars and suspending planets in an eternal universe except God as documented in Jewish Tanakh, Christian Bible and the Muslim Quran. Atheist and agnostic scientists or philosophers cannot refute the existence of God. Therefore, prophets and holy books testimony can be considered true until the nonbelievers prove it otherwise. Let this ball go to atheists court to coin proofs to prove reality of naturalism or refute the testimony of the existence of God.

\section{Nonexistence of God}

Atheists claim empirical inconsistencies and contradictions to exist in revelations within and among the holy-scriptures such as Tanakh, Bible and Quran and known facts as basis to reject existence of the Middle Eastern and Biblical deity called God. Quran says neither anyone born God nor He born anyone but Bible supports Jesus to be son of God. Atheist's theodicy that God being omnipotent and omni-benevolent should not allow existence of evil remains unreciprocated. Poor design question remains unrequited in the forms of fragile life, immune system and body defense system against disease attacks. Omnipotence paradox logical contradicts in questions like "Can God create a being more powerful than Himself" and "Telling something which He does not know". Both yes or no contradict omnipotence. Similarly, omnipotent and omniscient, All Knowing Being, deductively cannot change His mind. God has free will and has granted the same to His creations contradicts the existence of omniscience. If God knows the future, then humanity is destined to corroborate without having true free will to deviate. Transcendental concept for the no-existence of God contests the existence of an intelligent creator making logic, morality and science contingent which is incompatible with the presuppositionalist assertion that they are necessary. The cosmological argument (chicken or the egg) states that if the Universe had to be created by God because it must have a creator, then God, in turn, would have had to be created by some other God and the process continues to reoccur. Theological noncognitivism shows that God concept is unverifiable by scientific tests. There is a logical impossibility in theism: God being an extra-temporal has also an active creator. It suggests that very act of creation is inconceivable and absurd beyond the constraints of time and space. We being part of physical world contained within time and space cannot prove the existence of God.

Atheists inductively prove, J-P Sartre in Being and Nothingness, a being-for-itself (a consciousness) who is also a being-in-itself (a thing), self-contradictory which Salman Rushe's grimoire novel Grimus states "That which is complete is also dead". Atheists also insist that God's 
desire to create universe contradicts his omnipotence that He has no desire since the very concept of desire is subjectively human as explicitly espoused by Scott Adams in the book "God's Debris". Ancient revealed religions through miracles exhibiting prophets may subjectively be dismissed by witness of strong nonbelievers of the same earlier times. Conflicting religious accounts indicate contents from difference sources that means many of the religious reports may be either altered or man-made. An irrefutable example is that of trinity (trilemma) and incarnation. Hindus perception that Brahamman has transformed himself into universe is self-contradictory supposition of supernatural being. Statements of adopting belief of unknowable to prove its existence is also inherently flawed. Need for an answer argument states that If God needs no beginning and needs no end, why the cosmos requires a beginning and end to prove the existence of omnipotent God and apocalypse.

\section{Conclusions}

On issue of the existence of God the World community is divided into three camps namely theist (believers), atheists (nonbelievers) and agnostics (doubters). Theists are further divided into monotheists and polytheists, and others into stronger and weaker atheists and agnostics. Monotheists believe in Ultimate Creator but have small scale differences on capabilities of prophets and scents. This divides them in Jews and Muslims which further have minor differences in fine details of their faiths. Polytheists may be divided many types such as polytheists, pantheists and henotheists. Polytheists worship to more than one gods, pantheists (tolerating multiple gods) regard universe as a manifestation of god or identify god with the world and henotheists adhere to one out of several gods. All human being including theists, atheists and agnostics can neither prove nor refute the existence of God.

\section{References}

Abas, N., Kalair, A., \& Khan, N. (2015). Review of fossil fuels and future energy technologies. Futures, 69, 31-49. https://doi.org/10.1016/j.futures.2015.03.003

Abbott, A. (2002). Early Einstein manuscript set to make a relative fortune. Nature, 419(6903), $103-103$. https://doi.org/10.1038/419103b

Barnaby, W. (2009). Do nations go to war over water? Nature, 458(7236), 282-283. https://doi.org/10.1038/458282a Copan, P. (2003). The Rationality of Theism (1st ed.). Routledge.

Ferry, G. (2009). Science's new battle lines. Nature, 459(7243), 34-35. https://doi.org/10.1038/459034a

Hoodbhoy, P. (2009). An Indian history of numbers. Nature, 459(7247), 646-647. https://doi.org/10.1038/459646a

Jr., R. H. (2008). Questions that science can not answer. American Association for the Advancement of Science.

Khan, N.; Saleem, Z.; Abas, N. (2008). Endorsement of New SI Unit Prefixes for Space, Time, Energy and Matter. Lasers in Engineering, 18(1), 107-118.

Khan, N., Saleem, Z., \& Wahid, A. (2007). Review of natural energy sources and global power needs. Renewable and Sustainable Energy Reviews. https://doi.org/10.1016/j.rser.2007.04.007

Maududi, M. S. A. (2000). Tafsir ul Quran.

Plantinga, A. (1998). God, arguments for the existence. Routledge Encyclopedia.

Polkinghorne, J. (2003). Belief in God in an Age of Science. Yale University Press. 


\section{$5^{\text {th }}$ International Conference on Research in}

Behavioral and Social Science

Spain | Barcelona | December 7-9, 2018

Root, J. D. (1980). The Philosophical and Religious Thought of Arthur James Balfour (1848-1930). The Journal of British Studies, 19(02), 120-141. https://doi.org/10.1086/385758

Serageldin, I. (2009). Water: conflicts set to arise within as well as between states. Nature, 459(7244), $163-163$. https://doi.org/10.1038/459163b

Shamir, U., Grand, S., \& Grand, N. (2009). Water is a source of cooperation rather than war. Nature, 459(7243), 31-31. https://doi.org/10.1038/459031c

Stockl, A. (1883). Geschichte der neueren Philosophie.

Swinburne, R. (1997). Is There a God? (2nd ed.).

Wallach, J. (2007). Energy Crisis (1st ed.). Wellness Publications. 